\title{
Big Data on Adult Intelligence: 57 Years of the Seattle Longitudinal Study
}

Review of "Developmental Influences on Adult Intelligence: The Seattle Longitudinal Study"

by K. Warner Schaie

New York, NY: Oxford University Press, 2013.

Reviewed by Sophie von Stumm

Author Address Details:

Department of Psychology

Goldsmiths University of London

SE14 6NW London, UK.

Email: s.vonstumm@gold.ac.uk

This article may not exactly replicate the final version published in the APA journal. It is not the copy of record.' 
The Seattle Longitudinal Study (SLS) was initiated by K. Warner Schaie in 1956 and for more than half a century, it has provided unique insights into the nature and development of intellectual functioning in adulthood. Undoubtedly, it will continue to do so for many years to come because of its exceptional database:

The first SLS cohort - recruited in 1956 - consisted of 500 participants aged 22 to 67 years, who were members of the same health maintenance organisation and lived in the Seattle area. The cohort members were followed up in 7 year intervals - that is, in 1963, $1970,1977,1984,1991,1998$, and most recently in 2005. In addition to following-up the first cohort, new cohorts were recruited at each assessment wave. With that, the SLS comprises overall of 7 cohorts sampling a total of 4857 participants, of whom 26 were assessed 8 times, 86 were assessed 7 times, 139 were assessed six times, 262 were assessed 5 times, 371 were assessed 4 times, 591 were assessed 3 times, 1235 were assessed twice, and 2237 were assessed once between 1956 to 2005. At each assessment wave, participants completed extensive batteries of intelligence tests, including for example measures of inductive reasoning, word fluency, and perceptual speed, as well as plenty of other measures, such as information on demographic background, lifestyle, personality and health. These data are the basis of more than 100 scientific publications that inform today's knowledge of adult intellectual functioning. They also underlie Schaie's latest edition of "Developmental Influences on Adult Intelligence: The Seattle Longitudinal Study".

Throughout this book, Schaie follows a data-driven research approach that in turn shapes the conceptualization, structure and ultimately, the explanatory power of this volume. For example, the opening chapters are classified by research designs rather than by research topics or questions. Another example are the numerous graphs and tables, at occasion spanning more than 10 pages, that are presented throughout the book. While these allow for a thorough and detailed evaluation of the SLS database, they make for a droughty read. Later chapters that are devoted to specific topics, for example "health behaviours and intellectual functioning", comprise reprints of previously published studies. Their sequential aggregation exemplifies the continuity and comprehensiveness of the SLS research, and it again illustrates the methodological and data-based character of this volume. As a result, the book is an indispensible guide for all developmental psychologists - and those aspiring to be - with expertise in psychometrics; for others, the material will be challenging. 
Schaie's theoretical framework for the book comprises of five central questions: (1) How does adult intelligence develop? (2) At what age and how much do people decline in intelligence? (3) What are the generation-specific effects on intellectual development? (4) What explains age-related changes in adult intelligence? And (5) can interventions reverse cognitive decline?

Chapter by chapter, these questions are addressed with reference to SLS research. For question (1), Schaie concludes adult intelligence develops differently across individuals; for (2), he notes that people start to decline noticeable from the age of 60 years onwards and that these decrements in functioning are most prominent around the age of 80 years; for (3), he observes that older generations perform on average worse than younger generations, independent of age-related changes in intelligence; for (4), Schaie reports associations between numerous factors with age-related changes in intelligence, including for example lifestyle, health, and happiness; and for (5), he argues that age-related cognitive decline is associated with 'disuse' rather than 'loss' and thus, it might be reversed through educational interventions.

Many of these conclusions are undisputed; for example, the observation of generation-specific effects on intelligence falls in line with what is commonly known as the Flynn effect (Flynn, 1987). Others have been challenged. For example, so-called investment theorists of intelligence distinguished early on fluid intelligence, which refers to reasoning power, from crystallized intelligence that refers to knowledge and learned information (e.g. Ackerman, 1996; Cattell, 1941/ 1943). This distinction, which was partly rooted in the observation that fluid and crystallized intelligence developed differently over time with one declining early on (fluid) and the other increasing throughout adulthood (crystallized), is not mentioned in the book, despite its enduring significance and its implications for the assessment of adult intelligence. Another example is Schaie's enthusiasm for the efficiency of interventions to maintain, improve and restore adult intelligence, which is not generally shared amongst other intelligence researchers (Bielak, 2010). A broader embedment of the SLS findings in the psychological literature would have enabled a focused synthesis about the knowns and unknowns in intellectual development and thus, a clearer guide for future research efforts. 
Overall, this book paints a comprehensive picture of the history and findings of the SLS. It offers an SLS-based perspective on adult intelligence that captivates because of its extensive empirical basis.

\section{References}

Ackerman, P. L. (1996). A theory of adult intellectual development: Process, personality, interests, and knowledge. Intelligence, 22, 227-257.

Cattell, R. B. (1941). Some theoretical issues in adult intelligence testing. [Abstract] Psychological Bulletin, 38, 592.

Cattell, R. B. (1943). The measurement of adult intelligence. Psychological Bulletin, 40, $153-$ 193.

Bielak, A. A. M. (2010). How can we not 'lose it' if we still don't understand how to 'use it'? Unanswered questions about the influence of activity participation on cognitive performance in older age: A mini-review. Gerontology, 56, 507-519.

Flynn, J. R. (1987). Massive IQ gains in 14 nations: What IQ tests really measure. Psychological Bulletin, 101, 171-191. 